\title{
Restoring Competitors and Natural Enemies for Long-Term Control of Plant Invaders
}

\section{By Dana M. Blumenthal, Andrew P. Norton, and Timothy R. Seastedt}

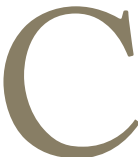

ontrolling invasive plants in rangeland is expensive, often prohibitively expensive. It wouldn't be, if the invaders didn't come back following management, but they do. There are reasons that invasive weeds invade, and unless those reasons are changed, they are likely to reinvade following control. This makes long-term management an uphill battle. The key to costeffective, long-term control is to address the underlying cause (or causes) of the invasion. Although those causes are typically not known, there are a couple of good bets. Chances are fair that a given invasive species is succeeding either because its competitors have been set back in some way, or because some of its enemies-insects and diseases - are missing, left behind when it was introduced from another continent. Restoring competition, enemies, or both can reduce an invasive species' success over the long term.

\section{Restoring Competitors}

In rangeland, unlike cropland, invaders have to succeed in the face of competition from native species that are well suited to local conditions. This can be tough. Inherently slow-growing, long-lived perennial species, whether native or introduced, are very good at reducing the resources available to other plants. They do not need as much water, nitrogen, or light to keep growing, so they can grow when fast-growing species cannot. Slow-growing species are therefore very competitive in environments with limited resources. Inherently fast-growing species, including many invasive species, arriving in resource-poor environments occupied by slow-growing species often cannot compete effectively.

But as soon as something stops the slow-growing species from taking up resources, either by killing them or just by setting them back, the fast-growing species have an opportunity. All sorts of disturbances can do this, but novel disturbances that native species are not used to are particularly likely to inhibit native species and provide opportunities for invaders. Examples include large-scale soil disturbances and novel fire or grazing regimes. From the perspective of a fast-growing species, the effects of such disturbances can be dramatic. Killing native rangeland species can more than double the amount of water and nitrogen available for plant growth. Disturbing the soil releases even more resources. And this sort of dramatic change can completely reverse competitive hierarchies. With plenty of resources, fastgrowing species outcompete slow-growing species, because they can get those resources more quickly. Thus disturbance gives fast-growing species, including many invasive species, an advantage.

Luckily, this process can be reversed, by reestablishing slow-growing species. For example, in Southeast Australia, overgrazing allows introduced annuals to replace the dominant native perennial, kangaroo grass (Themeda australis). ${ }^{1}$ Without intervention, the introduced annuals continue to dominate the site. However, when Themeda australis is restored using a combination of spring burning and seeding, it lowers soil nitrate by $50-75 \%$, and greatly reduces reinvasion by introduced annuals. Similarly, when tallgrass prairie in Minnesota is restored (using a combination of herbicide application, burning, tillage, and seeding) it is much more resistant to invasion by added weeds, with $72-92 \%$ lower weed biomass than grassland dominated by introduced perennial grasses (Fig. 1). ${ }^{2}$ Farther west, in central Wyoming, herbicide application, tillage, and revegetation with a variety of native and introduced perennial grasses reduced Russian knapweed (Acroptilon repens) cover by more than $80 \%$ relative to unseeded plots treated with herbicides and tillage. ${ }^{3}$

Of course, restoration is not easy. Paradoxically, the same plant traits that make many native grasses good competitors once they are established-slow growth, and the ability to keep growing with few resources-make them very difficult to get established. A variety of solutions have been proposed. The most common is using herbicides to reduce competition from fast-growing species, giving slow-growing species more time to become established. In some cases, well-timed burning or mowing can also reduce competition from invasive species and help natives to get established. ${ }^{1}$ In other 

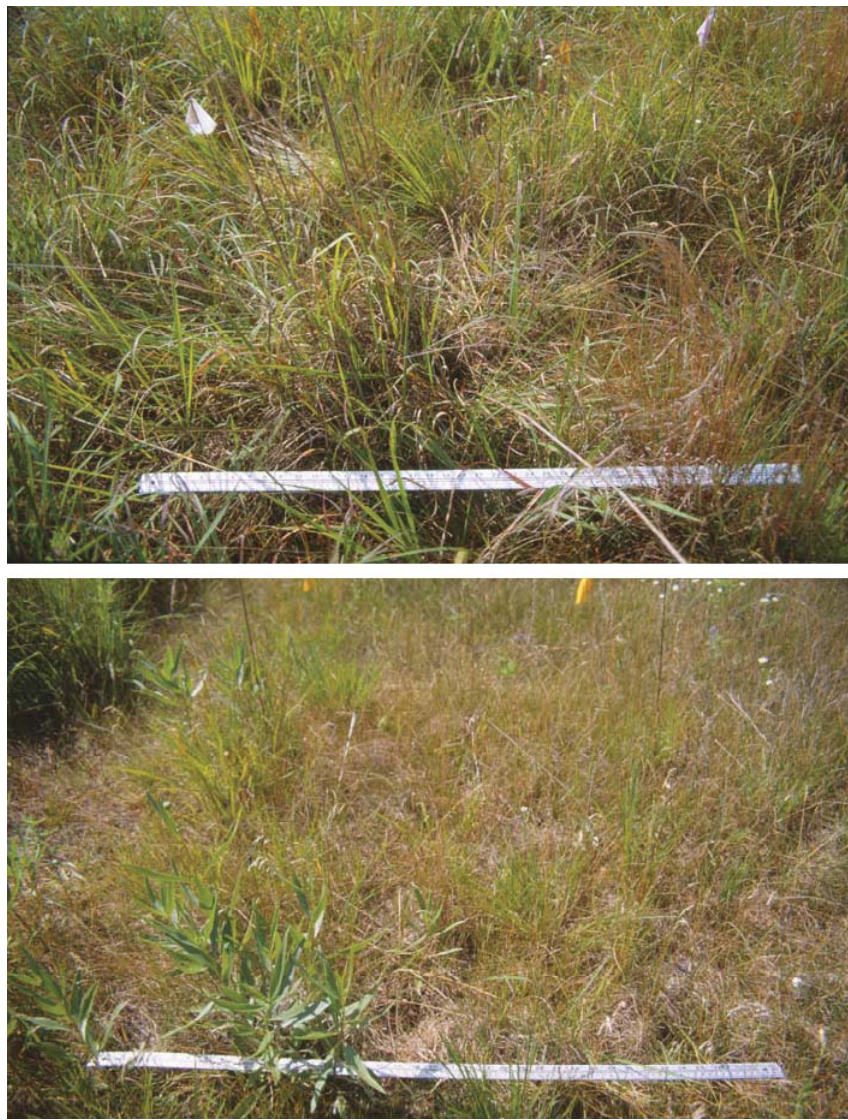

Figure 1. Restored tallgrass prairie dominated by native warm-season grasses (top) produces more biomass and resists weed invasion more effectively than a well-established old-field plant community dominated by introduced cool-season grasses (bottom). Photograph by Dana Blumenthal.

cases, such as cheatgrass (Bromus tectorum) invasion of shrubland, burning has to be prevented to give native species a chance. Other approaches that have been suggested to help slow-growing species get established include reducing resource availability (for example, by using carbon addition to reduce nitrogen availability; see Alpert, this issue), changing the timing or intensity of grazing, and seeding cover crops.

Choosing the right species, or combination of species, to restore is also important. Over the short term, species that are similar to dominant invasive species (for example fastgrowing species, or species with similar rooting patterns) may be most effective at competing against invasive species. ${ }^{4}$ But as restoration proceeds, and resource levels decline, slower-growing, later-successional species are likely to be more competitive. ${ }^{2}$ Consequently, one approach that has been suggested is to restore fast-growing species first, and then add slow-growing species once resource levels are lower and slow-growing species are more competitive. Another key question is whether to use native or introduced species for revegetation. Introduced species, such as crested wheatgrass (Agropyron cristatum), can be quite effective in suppressing invasive species. ${ }^{3}$ On the other hand, like the invasive species they replace, they can also reduce the diversity of native species and, depending on the objectives of the restoration, can even be considered invasive themselves.

\section{Restoring Competitors in the Face of Global Change}

Even within native species, the decision about which species will compete effectively against invaders is becoming increasingly complicated. Historically, native species could be assumed to be well suited to local environments. Native species have been around for a long time, long enough to become adapted to local environments, and long enough to have outlasted the many other species that have passed through the community. Local environments, however, are changing more rapidly than they have in the past, and as they do, this "home-field advantage" may decrease or even disappear. ${ }^{5}$

Predicting future environmental change is challenging. However, we do know what changes have occurred to date, and we can make some predictions for the future. The growing season in the western United States currently is about a month longer than it was 60 years ago, and this longer growing season is expected to persist and perhaps expand through this century. We also know that materials required by plants for growth-carbon dioxide and certain forms of nitrogen - are more abundant due to human activities. We know the least about precipitation trends, but given the overall warming, we would expect greater evapotranspiration from whatever precipitation occurs. Hence, most rangelands will likely be more arid than in the past century. Although there will be exceptions, the "warmer, drier, and more fertilized" environment is the target future environment for conservation and restoration efforts.

Not surprisingly, the above characteristics favor many invasive weeds. This trend occurs regardless of the control procedure. In spite of this handicap, however, there are examples of successful restorations, and there are some logical procedures to follow to enhance the probability that restored plant communities will outcompete invasive species.

\section{Limit Nutrients}

Native species in the western United States, on average, are more competitive in lower nutrient soils. Although manipulating soil nutrients can be costly, treatments applied for other reasons (e.g., prescribed burning, wood mulch application, etc.) can also reduce nutrient availability to plants under certain conditions. The goal is to create a nutrientpoor landscape that will contain, by design or accident, nutrient hotspots. This is the pattern that produced our historic levels of native biological diversity.

\section{Accept Multiple Alternative Outcomes}

Given our uncertain climate and uncertainties regarding precipitation in any year, use a "regional" mix of plant 
species that show the ability to grow in a range of very dry to above-normal moisture. This enhances the probability of generating a competitive plant community regardless of the vagaries of weather during and following the restoration effort. Although this type of seeding can be costly, doing nothing may ultimately cost more in terms of recurrent control requirements.

\section{Include Species for Future Environments}

Under increasing conditions of aridity, native subdominant species that become dominants during "normal" drought years are likely the desirable dominant species for the future. Look specifically to these species, as well as those that do best early on and late in the season (the species that are exploiting the expanded growing season), as candidates to be good competitors with invasive weeds.

\section{Consider Alternative Acceptable Community Types}

Native biodiversity is almost always maximized by activities that create heterogeneity. The vegetation itself can generate a portion of this heterogeneity. Although a site may have historically been a grassland, a mixture of grassland and shrubland species, or a novel combination of grassland species, may satisfy conservation goals (keeping all species at sufficient population densities) and be more effective at excluding undesirable species.

Thus, restoring competitors is difficult, particularly in the context of changing environments. Where it works, however, it is one of the few approaches that can yield long-term decreases in invasion. Like other control measures, it appears to work best as part of an integrated weed management strategy (see DiTomaso et al., this issue). For long-term control, the most promising control method to combine with restoration may be biological control. ${ }^{6}$

\section{Restoring Natural Enemies: Biological Control}

One of the reasons why introduced plants become invasive weeds is that they arrive in the introduced range without the insects and diseases that attack them (Fig. 2). The absence of these "natural enemies" can help introduced plants outcompete native rangeland vegetation. Because most insect herbivores and diseases are specialists, the insects and diseases native to the introduced range do not exert a substantial impact on many introduced plants. Without their specialist herbivores and pathogens, introduced plants can gain a competitive advantage over native species and dominate plant communities over a wider range of environmental conditions. Biological control seeks to remove this advantage, commonly referred to as "enemy release," by reuniting introduced plants with their original herbivores and diseases (Fig. 3). When successful, biological control can dramatically and permanently reduce the competitive ability and population densities of introduced invasive weeds. No other control technique is as specific to the weed target
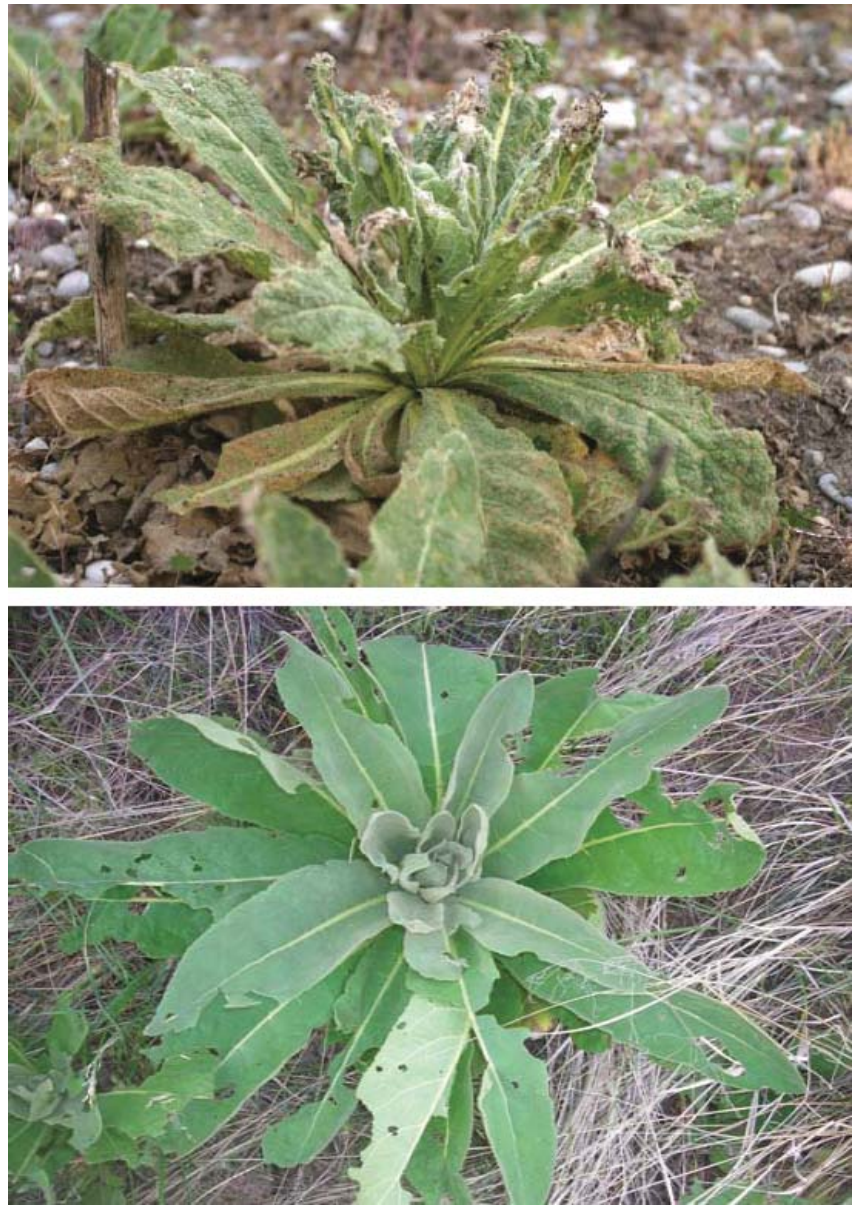

Figure 2. Mullein (Verbascum thapsus) rosettes in their native range (Switzerland, top picture) are typically heavily damaged by herbivores and diseases whereas those in their introduced range (Colorado, bottom picture) receive much lower levels of damage. Photographs by Andrew Norton and Christina Alba-Lynn.

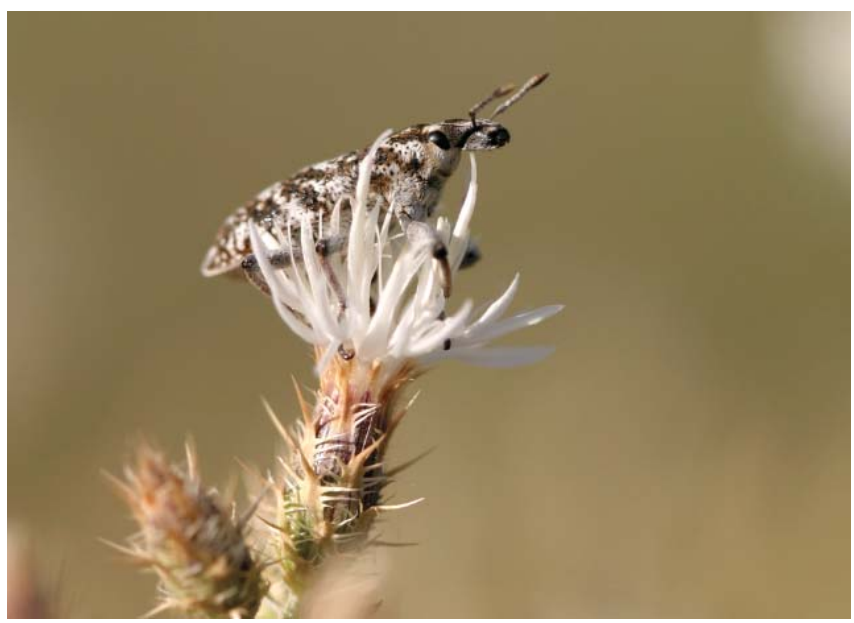

Figure 3. The root-feeding weevil, Cyphocleonus achates, on a diffuse knapweed (Centaurea diffusa) flower. C. achates is one of several biological control agents that can reduce populations of diffuse and spotted knapweed (Centaurea stoebe). Photograph by Andrew Norton. 
as biological control, and no other control technique is as self-perpetuating and permanent.

A key consideration in this process is ensuring that the introduced biological control agents are specific to the targeted weed and will not attack native or desirable vegetation. Prior to receiving permission for importation and release, candidate agents undergo several years of specificity testing on the target weed and nontarget vegetation. Current protocols for host-specificity testing have proven to reliably predict patterns of attack in the field. ${ }^{7}$ Examples of native plants that are attacked by intentionally introduced biological control agents (e.g., native thistle [Cirsium] species attacked by the thistle head weevil Rbinocyllus conicus, or native ragwort [Senecio] species attacked by the moth Tyria jacobaeae) were either predicted or could have been predicted by prerelease host-specificity tests, had they been required at the time of introduction. Recent releases, conducted under strict regulations, have an almost perfect safety record. Although no amount of testing can remove the risk associated with introducing new organisms, accumulated evidence suggests that careful prerelease testing leads to very low risk: benefit ratios.

Although biological control can be remarkably successful in controlling invasive plants, it only works sometimes. Predicting which species a biological control agent will feed on has proven much easier than predicting whether that feeding will in fact control the targeted species. Surveying 59 invasive plant biological control projects undertaken between 1903 and 1990, including many in rangeland ecosystems, Denoth and colleagues ${ }^{8}$ found that of the 202 arthropods that were released, $121(60 \%)$ established and only $59(29 \%)$ were deemed to have contributed to the reduction of the target species. Further, there is substantial variation in impact across the range of the targeted invasive plants. ${ }^{9}$ Although the success rate for individual agents is low, successes are more common when considered on a project-wide basis (all agents introduced against a weed target). In the above survey, $66 \%$ of biocontrol projects were described as "clearly successful." 8 Those successes include some invasive weeds that have been controlled across their entire range, and some that have been partially controlled, or controlled in some places but not others. Regardless of the level of control achieved, it tends to be maintained over the long term. As a result, the economic benefits of weed biological control programs far exceed the costs of project development and implementation. A recent estimate from Australian biocontrol programs undertaken since 1903 is that the benefit:cost ratio now exceeds 23:1 over all of the 33 programs undertaken. ${ }^{10}$

\section{Restoring Competitors and Enemies Together}

When biocontrol is successful, the next important question is what replaces the invasive weed. Biological control agents attack one or occasionally two or three closely related species. Successful biological control will reduce the competitive impact of the target invasive species on the surrounding vegetation. If that surrounding vegetation contains mostly desired species, biocontrol can be sufficient to allow those species to recover. On the other hand, if the surrounding vegetation or seed bank contains mostly other invasive plants, the likely outcome is that a new invader will replace the old one. In such cases, active restoration is essential for desired species recovery, even if biocontrol is entirely successful in controlling the target invader. Providing desired species to replace invaders is the most basic reason that biocontrol and restoration should be used together.

Biocontrol and restoration are also likely to work well together because they work against the same types of species. Restoring competitors controls fast-growing species. Biocontrol controls introduced species. However, the same fast-growing species that are most strongly inhibited by restoration may also be particularly susceptible to biocontrol. Fast-growing species adapted to habitats with high resource (e.g., light, water, nitrogen) availability can be toxic or unpalatable to generalist feeders but are often poorly defended against their coevolved specialist enemies. It is thought that they have evolved to regrow following damage from specialist herbivores rather than defend themselves against such damage. Fast-growing species therefore tend to be relatively heavily damaged by specialist enemies in their native range, and are likely to be heavily damaged when specialist enemies are reintroduced as biocontrol agents.

If fast-growing invasive plants are susceptible to both restoration of competitors and biocontrol, the combination of the two may provide the most effective control. Competition reduces the resources available to invasive plants, and should reduce their ability to survive and reproduce in the face of damage from biological control agents. On the other hand, reductions in resource availability can not only reduce invasive plant success, but also reduce invasive plant tissue quality and, potentially, the success of biocontrol agents.

Although the net effects of these different processes are not known, results from existing biocontrol releases are encouraging. McEvoy and Coombs ${ }^{6}$ directly tested the combination of competition and biocontrol on tansy ragwort (Senecio jacobaea). They found that either of two biological control agents, a moth (Tyria jacobaeae) and a flea beetle (Longitarsus jacobaeae), could successfully control the weed when competing vegetation was left intact. When plant competitors were removed, the ability of these herbivores to provide control was greatly reduced. More generally, in a review of past biocontrol programs, Denslow and D'Antonio ${ }^{9}$ found that successful programs tended to include additional control methods that increased competition from desired species.

In sum, restoring competitors and restoring natural enemies share the quality of permanence. Both rely on living organisms which, under the right conditions, can reduce 
invasive species performance indefinitely. Moreover, both approaches are likely to work against the same fast-growing invasive species and, more often than not, work well together. Neither restoring competitors nor restoring enemies is easy, but the potential benefits may be well worth the effort and risk.

\section{References}

1. Prober, S. M., And I. D. Lunt. 2009. Restoration of Themeda australis swards suppresses soil nitrate and enhances ecological resistance to invasion by exotic annuals. Biological Invasions 11:171-181.

2. Blumenthal, D. M., N. R. Jordan, and E. L. Svenson. 2005. Effects of prairie restoration on weed invasions. Agriculture Ecosystems and Environment 107:221-230.

3. Вотtoms, R. M., and T. D. Whitson. 1998. A systems approach for the management of Russian knapweed (Centaurea repens). Weed Technology 12:363-366.

4. Funk, J. L., E. E. Cleland, K. N. Suding, and E. S. Zavaleta. 2008. Restoration through reassembly: plant traits and invasion resistance. Trends in Ecology and Evolution 23: 695-703.

5. Seastedt, T. R., R. J. Новbs, and K. N. Suding. 2008. Management of novel ecosystems: are novel approaches required? Frontiers in Ecology and the Environment 6:547-553.

6. McEvoy, P. B., And E. M. Coombs. 1999. Biological control of plant invaders: regional patterns, field experiments, and structured population models. Ecological Applications 9: 387-401.

7. Pemberton, R. W. 2000. Predictable risk to native plants in weed biological control. Oecologia 125:489-494.

8. Denoth, M., L. Frid, and J. H. Myers. 2002. Multiple agents in biological control: improving the odds? Biological Control 24:20-30.

9. Denslow, J. S., and C. M. D’Antonio. 2005. After biocontrol: assessing indirect effects of insect releases. Biological Control 35:307-318.

10. McFayden, R. 2008. Return on investment: determining the economic impact of biological control programmes. In: M. H. Julien, R. Sforza, M. C. Bon, H. C. Evans, P. E. Hatcher, H. L. Hinz, and B. G. Rector [eds.]. Proceedings of the XII International Symposium on the Biological Control of Weeds. Wallingford, United Kingdom: CAB International. p. 67-74.

Authors are Research Ecologist, USDA Agricultural Research Service Rangeland Resources Research Unit, Fort Collins, CO 80526, USA, dana.blumenthal@ars.usda.gov (Blumenthal); Associate Professor, Dept of Bioagricultural Sciences and Pest Management and Graduate Degree Program in Ecology, Colorado State University, Fort Collins, CO 80523, USA (Norton); and Professor, Dept of Ecology and Evolutionary Biology, University of Colorado, Boulder, CO 80309, USA (Seastedt). 